\title{
NEWS
}

\section{Postdocs reap stem-cell funding benefits}

With the California Institute for Regenerative Medicine (CIRM) in its third year of doling out research grants, stem-cell scientists are starting to see the benefits of the 2004 ballot measure that gave the state a stem-cell research windfall. These advantages have not been limited to established researchers: the money is also giving postdocs rare opportunities, not only in terms of funding but also by providing avenues to independence.

The San Francisco-based institute, which was set up by the 2004 vote, announced on 29 April that it would give US $\$ 28$ million to support 17 basic stem-cell-biology grants. Other grants awaiting disbursal this year focus on transplantation immunology and clinical development. Voters approved stem-cell funding of $\$ 3$ billion over 10 years; to date, the CIRM has disbursed about $\$ 1$ billion.

Grants from the CIRM, including two training grants for graduate students, postdocs and clinical fellows, have given some early-career researchers quicker grant turnaround times and sought-after routes to independence. Aileen Anderson, an associate professor at the Sue and Bill Gross Stem Cell Research Center at the University of California, Irvine, says that her lab will soon hire two new postdocs as a direct result of her $\$ 1.28$ million, three-year CIRM grant. More significantly, she says, the grant has allowed her to create a co-investigator position for her most senior postdoc, Hal Nguyen. "A lot of postdocs are stuck - they can't move on because of the hiring freezes at many universities," says Anderson, noting that

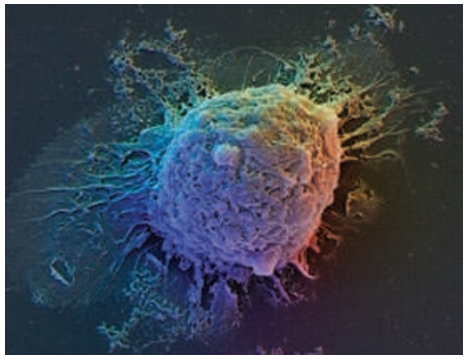

Stem-cell researchers are hiring. co-wrote the application. Zunder had thought of and developed the study idea - to examine pathway structures in specialized cells dedifferentiating into stem cells - on his own. "It grew directly out of his project," says Nolan. At Stanford, postdocs are not allowed to apply for Nguyen wants his own lab. grants, but Nolan says that "Now he has a glimmer of hope," she says. The grants require that recipients work in California, but collaborators can be anywhere.

The CIRM's quick turnaround is important for postdocs, grant recipients say. Postdocs who apply to the US National Institutes of Health often endure long waiting times, and grants may not come through until the postdoc has moved on to a new position. "Here, a postdoc can develop an idea and see it funded in a rapid way. I've never seen that before," says Garry Nolan, professor of microbiology and immunology at the Baxter Laboratory in Stem Cell Biology at Stanford University, Palo Alto, California. Nolan and his colleague Marius Wernig received a $\$ 1.45$-million four-year grant, for which Nolan's postdoc, Eli Zunder,
Zunder's grant-writing experience will prove useful in future.

Such benefits for postdocs are unlikely to slow for the next five years, according to a CIRM-funded economic-impact study conducted in 2008 by The Analysis Group, an economic and financial consulting agency headquartered in Boston, Massachusetts. The study authors analysed the 229 CIRM grants awarded up to September 2008 and found that each recipient, including 45 senior researchers recruited from outside California, had hired or planned to hire about 10 researchers, including postdocs. A new economic-impact study commissioned by the CIRM has not yet been released.

Karen Kaplan

\section{PROSPECTS}

\section{Faux scientist?}

\section{Having a laptop as a lab bench leads to mixed career prospects, says Bryan Howie.}

I may not be what many people think of when they imagine a scientist. I don't wear a white coat, mix chemicals or take measurements, and I don't form hypotheses or run experiments. I make tools.

Specifically, I write computer programs to help other scientists in their work. My signature program helps researchers to find genes that influence the risk of disease. This isn't just an exercise in computer coding: my colleagues and I have combined a wealth of experience in statistics and population genetics to build sophisticated models of the way in which genes are inherited over many generations. When applied thoughtfully, these models can increase the value of existing data sets and hasten the process of discovery.

Although I love making scientific tools, perhaps as a result of my undergraduate experience in an engineering department, I have some trepidation about staying on this track as I prepare to apply for jobs in academic research. On the whole, prominent journals tend to value data over methods, making it difficult to publish unless one's shiny new algorithm can ride on the coat-tails of an interesting data set - and even then there may be disputes about authorship. Access to cutting-edge data is also crucial to building a good tool in the first place, because it's hard to model data you've never seen. Partnerships between 'wet' and 'dry' labs can alleviate this concern and provide mutual benefits, but such relationships can be hard to establish, especially when you're a young toolmaker.

It is also immensely time-consuming to create and maintain a good software tool. Converting a statistical idea into a working computer program is the easy part; the hard part is accounting for unexpected input, anomalous data sets and specialized extensions, all while keeping the program fast and easy to use. These mundane chores are frustrating because I don't feel like I'm 'doing science' during the many hours they consume, which I would rather spend hatching new ideas, running analyses or writing papers. A widely used software tool represents a significant contribution to the field, but I worry that the time it takes away from publishing will damage my chances of landing a faculty job.

Nevertheless, I relish my role. Rather than being chained to a single line of enquiry, I contribute to many research projects at the same time. On learning that I am a human geneticist, people typically ask which disease I work on, and it is gratifying to say "most of them". My entire toolbox lives inside my laptop: instead of tending cell cultures on Saturdays or hovering over PCR machines under fluorescent lights, I can work wherever the sun is brightest and the coffee is thickest.

Toolmakers play an essential role in the scientific endeavour, and our importance will only grow as technological advances produce larger and more complex data sets. Still, sometimes I wonder: is tool-making a viable path to a career in academia?

Bryan Howie keeps a Postdoc Journal for Naturejobs and is a postdoctoral fellow in the Department of Human Genetics at the University of Chicago, Illinois. 